\title{
A Study on Goal Orientations, Self-Efficiency and Motivational Climate of Active Athletes with Sports Disabilities in Physical Education and Sports
}

\author{
Yesim Karaç Öcalı*, Turhan Toros², Rabia \\ Yildiz Öztürk ${ }^{2}$ \\ ${ }^{1}$ Department of Sports Sciences, Yozgat Bozok University, \\ Yozgat, Turkey \\ ${ }^{2}$ Department of Sports Sciences, Mersin University, Mersin, \\ Turkey \\ Study Area: Yozgat, Turkey \\ Coordinates: $39^{\circ} 49^{\prime} 15^{\prime \prime} \mathrm{N} ; 34^{\circ} 48^{\prime} 30^{\prime \prime} \mathrm{E}$
}

Keywords: Physical Performance, Mastery, Ego, Football

\section{Introduction:}

Nicholls et al. (1989) stated that individuals make an effort to achieve certain goals and achieve a sense of success when they achieve some goals. Athletes also set a number of goals and engage in various behavioural orientations to achieve these goals. These two goal orientations, which we call task and ego, are related to the way that individuals judge their ability levels. It has been stated that the individual who has task-oriented goals focuses on areas such as hard work, demonstrating mastery of the task, skill learning and skill development. It has been stated that individuals with egooriented goals make an effort to prove their superior ability. Sports research on achievement goals has been gathered in two areas. The first focused on individual differences in goal orientation preferences. Studies in this area have revealed the relationships between goal orientations and cognitive

\section{Abstract}

The research sample of this study consists of 151 male footballers who have been actively playing football in amateur football teams over the age of 18 who suffered from moderate and severe sports injuries in the last 3 years. Participation in the study was carried out on a voluntary and confidential basis. As data collection tools, Task in Sport and Ego Orientation Scale, The Perceived Motivational Climate Questionnaire in Sports and The General SelfEfficacy Scale were used. In the analysis of the data, the relational screening model, which included a comparison between variables and analysis of correlation type, was used. As a result, no significant difference between the position groups they played in the sub-factor scores of starting, not being afraid and persistent keep going, and there was no significant difference in the task and ego orientation questionnaire sub-factor scores according to the position groups they played. There was a positive significant relationship between the age variable and the baseline sub-factor score, while a significant negative correlation was found between the age variableand the keep going sub-factor score. There was a positive significant relationship between the non-indignity sub-dimension, while there was a significant negative relationship between age and ego orientation scores. On the other hand, a significant positive correlation was found between sports age and performance climate and sports age.

and emotional characteristics (Duda \& Nicholls, 1989). The second is the study of situational factors. The relationship between the structure of the learning environment and goal orientations and motivations has been examined (Ames \& Archer, 1988). Although studies have examined individual factors and situation factors separately, it has shown that there is a strong link between both areas and that both have effects together (Duda et al., 1995). It has been found that athletes' effective use of strategies, competitive preferences, positive attitudes towards learning and their effort was observed more in the mastery motivational climate (Ames \& Archer, 1988). Papaioannou (1994) stated that the perceived motivational climate is a factor in explaining the athlete's goal orientation. Self-efficacy judgments affect what activities we will take part in, how much effort we will make in the face of a situation, and our emotional reactions 
at the moment (Tokinan \& Bilen, 2011). The theoretical basis of self-efficacy is based on social learning (sociocognitive) theory developed by Bandura (1977). Bandura (1977) first mentioned the concept of self-efficacy in the article "Self-efficacy: Toward a unifying theory of behavioural change". Then, in 1986, he placed the concept of self-efficacy into "Social Learning Theory" and in 1997, he was told that self-efficacy works in harmony with other social learning factors that regulate human success and well-being stated that it is within the center theory (Bandura, 1977; Pajares, 1997). Strong self-efficacy is an element that makes people happy and successful. People who doubt their own capacity shy away from difficult tasks and view them as threats. They are not willing and take little responsibility for their goals (Bandura, 1994; Bandura, 1997).

The individuals who have negative self-efficacy perceptions avoid hard work, give up quickly in the face of difficulties, and fail by performing poorly with more stress (Tschannen-Moran \& Hoy, 20o1). Studies in different groups in the literature revealed that general self-efficacy perceptions significantly predict life satisfaction (Vecchio et al., 2007; O'Sullivan, 2011; Lightsey et al., 2013; Özbay et al., 2012; Telef \& Ergün, 2013). From these findings, it can be said that individuals with positive self-efficacy perceptions get more satisfaction with their lives. If the individual's selfefficacy beliefs are firmly established, the individual is more resistant to changes (Morgil et al., 2004).

\section{Materials and Methods:}

Relational screening model is a method that aims to reveal the existence, degree and direction of change between two or more variables, which is one of the general scanning model types that aims to describe an existing situation as it is. In this study, comparison and correlation type scanning models, which are sub-categories of relational scanning models, were used (Karasar, 2015).

The universe of the study consists of active licensed male footballers with a background of injury who study in the Department of Physical Education and Sports. In the sample of the research; In Adana, Karaman, Ankara, Mersin, Antalya, Konya, there are active amateur footballers over the age of 18 who have been studying in the physical education and sports department and have experienced moderate and severe sports injuries in the last 3 years. One hundred and fifty-one football players whose ages ranged from $20-31$ years $($ Xage $=25.42 \pm 3.04$ ) and sports ages between 3-13 years (Xsportsage $=7.41 \pm 3.62$ ) participated voluntarily in the study.

The data used in the study were collected by the researchers themselves. During the data collection process, the necessary explanations were made to the participants by the researcher for the purpose, scope of the research and to protect the confidentiality of the information to be obtained. Participants voluntarily participated with an informed consent form according to the Helsinki criteria. The ethics committee was consulted for this study and the necessary permissions were obtained. Only actively licensed footballers with a disability background studying in the physical education and sports department were included in the study.

Data Collection Tools: "Personal Information Form" containing questions such as age, sports age, position they played was distributed to the participants in order to determine their demographic characteristics.

Task and Ego Orientation Questionnaire in Sports: the questionnaire was developed by Duda \& Nicholls (1992). According to the task and ego orientation questionnaire in sports, it consists of 13 question items, 6 of which are oriented towards ego orientation. Respondents of the scale make their participation in each item according to the fivepoint Likert evaluation system. In the original study on the scale, the internal consistency of the scale was determined as 79 for task orientation, 81 for ego orientation, and the three-week test-retest reliability of the scale was found to be 68 for task orientation, and 75 for ego orientation (Duda \& Nichols, 1992). The scale was adapted for Turkish Athletes by Toros (2001). In the adaptation study by Toros (2001), two factors, task and ego orientation, explained $58 \%$ of the overall variance, and the internal consistency values calculated by cronbach and alpha were .87 for task orientation, .85 for ego orientation, and three-week testretest reliability .65 for task orientation and .72 for ego orientation. For this study, internal consistency values calculated with cronbach and alpha were found to be .75 for task orientation and .82 for ego orientation.

Perceived Motivational Climate Questionnaire in Sports: the scale was developed by Walling et al. (1993). The Motivational Climate Scale perceived in sports consists of 21 items, nine of which are performance and twelve are mastery climate. Respondents of the scale make their participation in each item according to the five-point Likert evaluation system. In the original study of the scale, construct validity was done with the help of both explanatory and confirmatory factor analysis (Walling et al., 1993). The scale is used to reveal individual differences in mastery and performance climate dimensions in determining motivational climates. The scale was adapted for Turkish athletes by Toros (2001). In the adaptation study of Toros (2001), the internal consistency values calculated by the cronbach alpha, in which the mastery and performance climate dimensions explained $51 \%$ of the overall variance of the scale, were .84 for mastery climate, .90 for performance, and 3-week test-retest reliability for mastery climate, .66. For the performance climate, it turned out to be .74. For this study, internal consistency values calculated with Cronbach alpha were found to be .87 for mastery climateand 89 for performance. 
General Self-Efficacy Scale: the General Self-Efficacy Scale, one of the data collection tools of the study, was created by Sherer et al. (1982) as 23 items. The scale, which consists of a two-factor structure, Social Self-efficacy and General Self-Efficacy. The scale was converted into a 5 'likert type scale with a study conducted by Sherer \& Adams (1983), and the increase of the scores on the scale means the increase of self-efficacy. The General Self-Efficacy Scale, which was firstly made into 17 items by Magaletta \& Oliver (1999) was adapted to Turkish culture (Yildirim \& Ilhan, 2010). This process, the researchers evaluated the scale in terms of cultural appropriateness, understandability and suitability with the support of academicians who are experts in psychology, psychiatry, linguistics, and sociology. Yildirim \& Ilhan (2010) determined the criterionbased validity of the scale and used exploratory factor analysis and varimax rotation to determine the factor structure. Exploratory factor analysis results indicate 3 factors with eigenvalues greater than 1 . Pearson correlation coefficient of the scale's test-retest reliability coefficient shows that there is a moderate and significant correlation $(\mathrm{r}=.8 \mathrm{o}, \mathrm{p}<.001)$. The split half reliability regarding the study was determined as .77. Split half reliability and Cronbach alpha coefficients indicate that the scale is reliable (Yildirim \& Ilhan, 2010). In the reliability study conducted within the scope of this study, the internal consistency coefficient of the General Self-Efficacy Scale was found to be .78 for the starting sub-dimension, .87 for the endure sub-dimension .91 for the keep going sub-dimension.

Data Analysis: as a result of the normality test, the Kolmogorov Smirnov value of goal orientation, motivational climate and self-efficacy scores according to age, sports age and position status was not found significant ( $p>.05)$. As a result of the normality test, the distribution was found to be normal, and the One-Way ANOVA test was used for statistical analysis for comparisons of more than two groups, and the Pearson Correlation Coefficient was used to look at the relationship status.

Results:
There was no significant difference in the sub-factor scores of starting. endure and keep going according to the position groups they played (Table-1).

There was no significant difference in the task and ego orientation sub-factor scores according to the position groups they played (Table-2).

There is no significant difference in mastery and performance climate sub-factor scores according to the position groups they play (Table-3).

Table 4 . The relationship between the general self-efficacy scale scores of the study group and age and sports age variables

\begin{tabular}{lll}
\hline & Age & Sports Age \\
\hline Starting & $.545^{* *}$ & .084 \\
Endure & .074 & $.182^{*}$ \\
Keep Going & $-.391^{* *}$ & $.047 \quad{ }^{*} \mathrm{p}<.05 ;{ }^{* *} \mathrm{p}<.01$ \\
\hline
\end{tabular}

A positive significant relationship was found between the age variable of the study group and the baseline subfactor score, while a significant negative correlation was found between the age variable and the keep going subfactor score. There was no correlation between the score of starting and maintaining keep going sub-factors, but a positive significant relationship was found between the sub-dimension of endure.

Table-5: Relationship between goal orientation scale scores of the study group and age and sports age variables

\begin{tabular}{llll}
\hline & Age & \multicolumn{2}{l}{ Sports Age } \\
\hline Task Orientation & .154 & .048 & \\
Ego Orientation & $-.191^{*}$ & .097 & ${ }^{*} \mathrm{p}<.05$ \\
\hline
\end{tabular}

No significant relationship was found between the age variable characteristics of the study group and the task orientation sub-factor scores. A significant negative correlation between age \& ego orientation scores (Table-5).

Table-6: The relationship of the motivational climate scale scores of the study group with the age and sports agevariables

\begin{tabular}{llll}
\hline & Age & \multicolumn{2}{l}{ Sports Age } \\
\hline Mastery Climate & 0.53 & .071 & \\
Performance Climate & -.142 & $.184^{*}$ & ${ }^{*} \mathrm{p}<, 05$
\end{tabular}

Table 1. Comparison of the general self-efficacy scale scores of the study group in terms of their positions.

\begin{tabular}{|c|c|c|c|c|c|c|c|c|c|c|}
\hline \multicolumn{6}{|c|}{$f, x, s s$} & \multicolumn{5}{|c|}{ ANOVA Results } \\
\hline Score & & $N$ & $X$ & ss & & $K T$ & $S d$ & KO & $F$ & $P$ \\
\hline \multirow[t]{4}{*}{ Starting } & Defense & 67 & 27.12 & 3.07 & Between groups & 386.28 & 2 & 193.14 & 1.98 & .139 \\
\hline & Midfield & 58 & 25.84 & 2.7 & In-group & 37610.77 & 148 & $97 \cdot 44$ & & \\
\hline & Attack & 26 & 28.11 & 2.98 & Total & 37997.05 & 150 & & & \\
\hline & Total & 151 & 25.42 & 1.23 & & & & & & \\
\hline \multirow[t]{4}{*}{ Endure } & Defense & 67 & $20.5^{2}$ & 2.13 & Between groups & 286.46 & 2 & 143.23 & 1.31 & .271 \\
\hline & Midfield & 58 & 18.92 & 3.01 & In-group & 42154.21 & 148 & 109.21 & & \\
\hline & Attack & 26 & 19.41 & 2.98 & Total & 42440.67 & 150 & & & \\
\hline & Total & 151 & 18.42 & 1.45 & & & & & & \\
\hline \multirow[t]{4}{*}{ Keep Going } & Defense & 67 & 10.54 & 2.14 & Between groups & 284.61 & 2 & 142.31 & 1.30 & .273 \\
\hline & Midfield & 58 & 12.92 & 1.15 & In-group & 42156.06 & 148 & 109.21 & & \\
\hline & Attack & 26 & $9 \cdot 98$ & 2.65 & Total & 42440.67 & 150 & & & \\
\hline & Total & 151 & 11.24 & 2.21 & & & & & & \\
\hline
\end{tabular}


Table-2: Comparison of the study group's goal orientation scale scores in terms of their positions

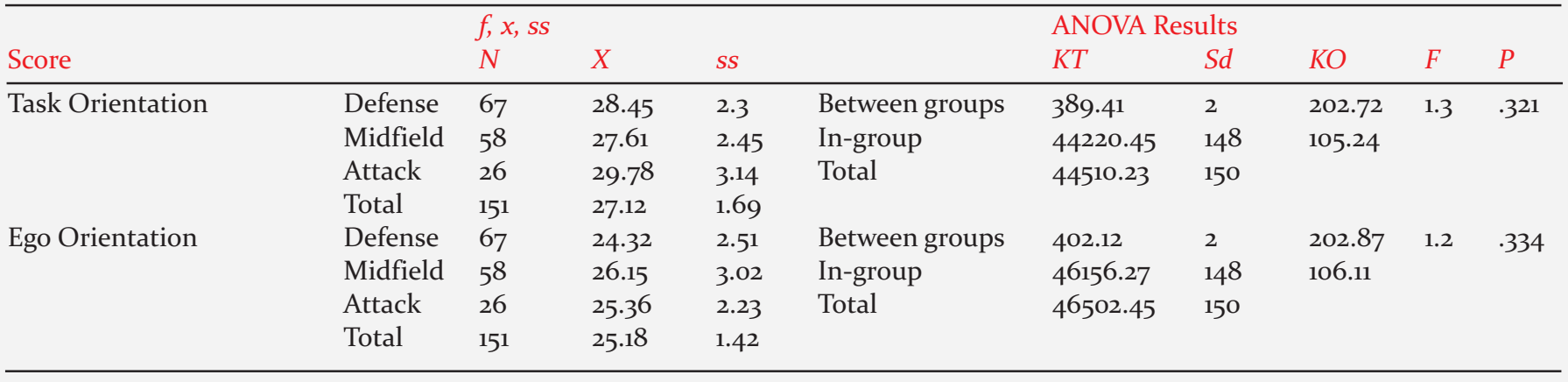

Table 3. Comparison of the motivational climate scale scores of the study group in terms of their positions

\begin{tabular}{|c|c|c|c|c|c|c|c|c|c|c|}
\hline \multirow{2}{*}{ Score } & \multicolumn{3}{|c|}{$f, x$, ss } & \multirow[b]{2}{*}{ sS } & \multirow[b]{2}{*}{ Var. $K$. } & \multicolumn{3}{|c|}{ ANOVA Results } & \multirow[b]{2}{*}{$F$} & \multirow[b]{2}{*}{$P$} \\
\hline & & $N$ & $X$ & & & KT & $S d$ & KO & & \\
\hline \multirow[t]{4}{*}{ Mastery Climate } & Defense & 67 & 21.88 & 3.01 & Between groups & 388.27 & 2 & 195.22 & 2.01 & .129 \\
\hline & Midfield & 58 & 25.84 & 3.42 & In-group & 36120.45 & 148 & 98.33 & & \\
\hline & Attack & 26 & 30.02 & 2.98 & Total & 36990.05 & 150 & & & \\
\hline & Total & 151 & $25 \cdot 42$ & 3.04 & & & & & & \\
\hline \multirow[t]{4}{*}{ Performance Climate } & Defense & 67 & 21.88 & 3.01 & Between groups & $289 \cdot 33$ & 2 & 138.77 & 1.29 & .275 \\
\hline & Midfield & 58 & 25.84 & 3.42 & In-group & 42156.21 & 148 & 101.95 & & \\
\hline & Attack & 26 & 30.02 & 2.98 & Total & 42500.67 & 150 & & & \\
\hline & Total & 151 & $25 \cdot 42$ & 3.04 & & & & & & \\
\hline
\end{tabular}

There was no correlation between sports age and mastership climate sub-dimension score, a positive significant correlation was found between performance climate and sports age (Table-6).

\section{Discussion:}

There was no significant difference between the position groups they played in the sub-factor scores of the study group was starting, endure and keep going. There was no significant difference in the task and ego orientation subfactor scores of the study group according to the position groups they played. There was no significant difference in mastery and performance climate sub-factor scores of the study group according to the position groups they played. Correlations with psychological skills have been found in studies examining players in different positions of the same sport (Cox \& Yoo, 1995). The demands expected from the athletes differ depending on the function of the player position. In team sports, there were studies reporting that some psychological characteristics should be used besides the motivational climate score in determining the position where the athlete would play and that determining the position without addressing physical, psychological and conditional factors would be wrong (Grobbelaar \& Potgieter, 2007; Jooste et al., 2014). It was stated that the performance climate and mastery climate scores did not differ significantly according to the positions of the players (Kesmis et al., 2020). Also, Kesilmis \& Yildiz (2018) determined body awareness and achievement goals related to track and field athletes participating in the European Champion Clubs Cup in Mersin. There were statistically significant positive correlations between body awareness and both mastery avoidance and performance-avoidance.
There was a positive significant relationship between the age variable of the study group and the baseline subfactor score, while a significant negative correlation was found between the age variable and the keep going subfactor score. When we examined sports age, there was no correlation between the score of the starting and maintaining keep going sub-factors, but a positive significant relationship was found between the nonresilience sub-dimension. When the self-esteem of the injured athletes during and after the injury was compared by Aydogan (2014), it was found that the self-esteem of the athletes increased with their return to the field during the treatment process. Berger \& Owen (1983) report that there was a linear relationship between exercising and participating in physical activity and self-esteem and selfperception. This study supports our results. After the treatment, the return of the athletes to their friendship, starting training and feeling that they are ready to go to the matches draw attention as important factors that increase their self-image while also increasing their self-esteem.

There was no significant relationship between the age variable characteristics of the study group and task orientation sub-factor scores. Again, there was no significant relationship between sports age and task and ego orientation sub-scores. There was a significant negative correlation between age and ego orientation scores. Toros (2002) states that education level can be effective on task and ego orientation levels, high school age athletes are egooriented, whereas university recreational athletes are more task-oriented. Altintas et al. (2012) stated that goal orientation score and perceived motivational climate score are not affected by the level of sports experience, but Toros 


\section{ORIGINAL ARTICLE}

(2002) states that the level of sports experience may cause differentiation on task orientation, ego orientation, performance climate and mastery climate scores. According to Toros (2002), while elite basketball players were oriented towards performance climate, non-elite basketball players are oriented towards mastery climate. On the other hand, Carpenter \& Yates (1997) stated that the task orientation scores of amateur football players are higher than semi-professional football players, and that there was no statistically significant difference between their ego orientations, although they were higher in semiprofessional athletes. According to Ariburun \& Asçi (2005), in American football players; There was no positional difference between the mastery climate, ego-task orientation scores. In contrast, the performance climate score is higher for offensive players than for defenders.

No correlation was found between the age variable of the study group and mastery and performance climate subdimensions of the motivational climate scale. While there was no correlation between sports age and mastership climate sub-dimension score, a positive significant relationship was found between performance climate and sports age. Flores et al. (2008) observed a decrease in egogoal orientation with age. In the literature, similar studies indicate that there is a significant difference between a task and ego orientations and age (Çavdarli, 2013; Duda, 1998). As the duration of doing sports increases, the athletes increase their match experience by playing more competitions. Üngör (2009) found there were strong correlations between job orientation and mastery climate, ego orientation and performance climate in both amateur and professional football players with various independent variables. found that the performance climate averages were significantly higher than those of professional football players. Similarly, Duda (1998) obtained strong correlations between perceived motivational climate variables and athletes' goal orientation. Individual goal orientation is strengthened, weakened or sometimes reversed by the effect of motivational climatic factors (Toros, 2002). Öntürk et al. (2018) found that participants who participate in sports have higher target commitment scores compared to those who do not.

As a result, updating the study with different sports branches by adding various variables to the goal orientation, self-efficacy and motivational climate of football players studying in physical education departments will be beneficial in terms of literature information. In addition, the proliferation of research in this field, the increase of comments, discussions and suggestions to be put forward will make important contributions to the relevant literature information.

\section{References:}

Altintas, A., Bayar Koruç, P., \& Akalan, C. (2012): Sporcularin hedef yönelimleri, algilanan güdüsel iklimleri ve algilanan fiziksel
Ambient Science, 2020: Vol. 07(Sp1); 360-365 DOI:10.21276/ambi.2020.07.sp1.oa48

yeterliklerinin cinsiyete ve deneyim düzeyine göre karsilastirilmasi. Türkiye Klinikleri Spor Bilimleri, 4(1):1-15.

Ames, C., \& Archer, J. (1988): Achievement goals in the classroom: Students' learning strategies and motivation processes. I. Edu. Psychol., 8o(3):260.

Ariburun, B., \& Asçi, H. (2005): A study of goal orientation and motivational climate in american football. Sportmetre Beden Egitimi ve Spor Bilimleri Dergisi, 3(3):111-114.

Aydogan, Z.Y. (2014): Psychological changes in athletes during injury and after treatment. Master of Science Thesis, Health Science Institute, Ankara University.

Bandura, A. (1977): Self-efficacy: toward a unifying theory of behavioral change. Psychol. Rev., 84(2):191.

Bandura, A. (1994): Social Cognitive Theory and Exercise of Control over HIV Infection. In: DiClemente R.J., Peterson J.L. (eds) Preventing AIDS. AIDS Prevention and Mental Health. Pub. by: Springer, Boston, MA

Berger, B.G., \& Owen, D.R. (1983): Mood alteration with swimming—swimmers really do" feel better". Psychos. Med., 45:425-433.

Carpenter, P.J., \& Yates, B. (1997): Relationship between achievement goals and the perceived purposes of soccer for semiprofessional and amateur players. I. Sport Exerc. Psychol., 19(3):302-311.

Cox, R.H. \& Yoo, H.S. (1995): Playing position and psychological skill in American football. J. Sport Behav., 18(3):183-194.

Çavdarli, S. (2013): Relationship between high school athletes' task and ego orientations and coping with stress strategies in sport. Master Thesis, Mersin University, Saglik Bilimleri Enstitüsü, Mersin.

Duda, J.L. (1998): Advances in Sport and Exercise Psychology Measurement. Pub. by: Fitness Information Technology, Morgantown.

Duda, J.L., \& Nicholls, J.G. (1989): The task and ego orientation in sport questionnaire: Psychometric properties. Unpublished manuscript, 1-13.

Duda, J.L., \& Nicholls, J.G. (1992): Dimensions of achievement motivation in schoolwork and sport. J. Edu. Psychol., 84(3):290.

Duda, J.L., Chi, L., Newton, M.L., \& Walling, M.D. (1995):Task and ego orientation and intrinsic motivation in sport. Int. J. sport Psychol., 26:40-63.

Flores, J., Salguero, A. \& Márquez, S. (2008): Goal orientations and perceptions of the motivational climate in physical education classes among Colombian students, Teach. Teacher Edu., 6:1441-1449

Grobbelaar, H. \& Potgieter, J.C. (2007): Positional differences in the sport psychological skill levels and attributes of rugby union players. Af. J. Phys. Health Edu. Recreat. Dance, 321334.

Jooste, J, Steyn, B.J.M, \& Van Den Berg, L. (2014): Psyhological skills, playing positions and performance of African youth soccer teams. S. Af.J. Res. Sport, Phys. Edu. Recreat, 36(1):85100.

Karasar, N. (2015). Scientific Method. Pub. by: Nobel Publishing, Ankara. 
Kesilmis, I., Tastan, Z. \& Toros, T. (2020): Comparison of perceived motivational climate and positive feedback of football players according to positions. J. Sport. Edu., 4(1):115-122.

Kesilmis, I. \& Yildiz, R. (2018): The relation between body awareness and track and field athletes' goal setting.J. Human Sci., 15(4):2454-2461.

Lightsey, O.R., McGhee, R., Ervin, A., Gharghani, G.G., Rarey, E.B., Daigle, R. P., Wright, K.F., Constantin, D. \& Powell, K. (2013): Self-efficacy for affect regulation as a predictor of future life satisfaction and moderator of the negative affect-Life satisfaction relationship. J. Happi. Stud., 14(1):1-18.

Magaletta, P.R., \& Oliver, J.M. (1999): The hope construct, will, and ways: Their relations with self-efficacy, optimism, and general wellbeing. J. Clin. Psychol., 55(5):539-551.

Morgil, I., Seçken, N., \& Yücel, A.S. (2004): Based on some investigation of self-efficacy beliefs of preservice chemistry teachers variables. J. BAUN Inst. Sci. Technol., 6(1),:62-72.

Nicholls, J.G. (1992): The general and the specific in the development and the expression of achievement motivation (pp. 31-56). In G. C. Roberts (Ed.), Motivation in Sport and Exercise. Pub. by: Human Kinetics, Champaign, IL

Nicholls, J.G., Cheung, P.C., Lauer, J., \& Patashnick, M. (1989): Individual differences in academic motivation: Perceived ability, goals, beliefs, and values. Learn. Indiv. Diff., 1(1):63-84.

O'Sullivan, C. (2011): Particulate discrete element modelling: a geomechanics perspective. Pub. by: CRC Press.

Öntürk, Y., Bingöl, E., Gürel, A.G. \& Çaglayan, A. (2018): Investigation of corporate target donations of the administrative staff at university. J. Soc. Human. Sci. Res., 30(5):4016-4021.

Özbay, Y., Palanci, M., Kandemir, M., \& Çakir, O. (2012): Üniversite Ögrencilerinin Öznel Iyi Oluslarinin Duygusal Düzenleme, Mizah, Sosyal Öz-Yeterlik Ve Basaçikma Davranislari Ile Yordanmasi.J. Turk. Edu. Sci., 10(2):325-345.

Pajares, F. (1997): Current directions in self-efficacy research. $A d v$. Motiv. Achiev., 10(149):1-49.

Papaioannou, A. (1994): Development of a questionnaire to measure achievement orientations in physical education. Res. Quart. Exerc. Sport, 65(1):11-20.
Sherer, M., \& Adams, C.H. (1983): Construct validation of the selfefficacy scale. Psychol. Rep., 53(3):899-902.

Sherer, M., Maddux, J.E., Mercandante, B., Prentice-Dunn, S., Jacobs, B., \& Rogers, R.W. (1982): The self-efficacy scale: Construction and validation. Psychol. Rep., 51(2):663-671.

Telef, B.B., \& Ergün, E. (2013): Self-efficacy as a predictor of high school students' subjective well-being. Kuramsal Egitimbilim 6(3):423-433.

Tokinan, B.Ö., \& Bilen, S. (2011): The effects of creative dancing activities on motivation, self-esteem, self-efficacy and

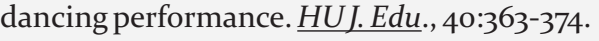

Toros, T. (2001): Effects of goal orientation, motivational climate, the degree of difficulty and properties of goal to life satisfaction in elite and non-elite male basketball players. Master Thesis, Health Sciences Institute, Mersin University, Mersin.

Toros, T., (2002): Goal orientation, motivational climate and life satisfaction among elite and non-elite male basketball players in Turkey. Hacettepe J. Sport Sci., 13(3):24-36.

Tschannen-Moran, M., \& Hoy, A.W. (2001): Teacher efficacy: Capturing an elusive construct. Teach. Teach. Edu., 17(7):783805 .

Üngür, G. (2009): The relationship between goal orientation and perceived motivational climate in amateur and professional footballers. Master Thesis, Health Sciences Institute, Ege University, Izmir.

Vecchio, G.M., Gerbino, M., Pastorelli, C., Del Bove, G., \& Caprara, G.V. (2007). Multi-faceted self-efficacy beliefs as predictors of life satisfaction in late adolescence. Person. Indiv. Diff., 43(7):1807-1818.

Walling, M.D., Duda, J.L., \& Chi, L. (1993): The perceived motivational climate in sport questionnaire: Construct and predictivevalidity. J. Sport Exer. Psychol., 15(2):172-183.

Yildirim, F., \& Ilhan, I.Ö. (2010): The validity and reliability of the general self efficacy scale Turkish form. Turk. I. Psych., 21(4):301-308. 